REVIEW

\title{
Michael Cart's Young Adult Literature: From Romance to Realism (3rd edition)
}

\author{
TERRI SUICO \\ SAINT MARY'S COLLEGE
}

Like the adolescents it speaks to, young adult literature (YAL) has undergone some tumultuous times in its 70-plus years of existence. It has had its share of growing pains and awkward moments, and it has also had periods, such as the present, of brilliance. The late 1990s saw a revival of YAL, and the 2000s ushered in what YAL expert Michael Cart has referred to numerous times as "a new golden age" (Cart, 2001, p. 96). From the highly-anticipated arrival of the play Harry Potter and the Cursed Child, rooted in the beloved series by J.K. Rowling, to the excitement surrounding Turtles All the Way Down, John Green's first book after The Fault in Our Stars, YA books are an integral part of the zeitgeist.

Given this, it might be difficult to believe that, just two decades ago, many in publishing were predicting the end of YA books. At the time, with the number of book titles declining and the quality of many books considered questionable, the category seemed to be on its last legs. During a panel of YAL leaders at the 1994 Young Adult Library Services Association conference, Linda Zuckerman stated, "I think young adult literature is dying" (Cart, 2016, p.59). In the face of this bleak outlook, the first edition of Michael Cart's seminal examination of YAL's history and then-current state, From Romance to Realism: 50 Years of Growth and Change in Young Adult Literature, was published in 1996. He ended the book with equal parts defiance and pleading, stating:

We cannot permit young adult literature to be silenced. Everyone who cares about literature and about young people has a dead-serious responsibility to focus attention on, support, and defend the very best, most courageously outspoken, and bluntly honest of young adult books. By so doing, we strengthen its voice; we amplify it so that it can be 
heard by those who most need to hear it: the most-at-risk-ever young adults themselves. (p. 278)

As time has shown, others agreed with Cart and helped make the 2000s a time of unprecedented growth in YAL publishing and scholarship.

Since the first edition of From Romance to Realism, the landscape of YAL and publishing has changed enormously. Fortunately for the teachers, librarians, scholars, and readers of YA books, Cart has responded to this with new, updated editions of his book. In 2010, the American Librarian Association published an updated and retitled Young Adult Literature: From Romance to Realism, followed by the third, and most recent, edition in 2016. This third edition continues the proud tradition of the earlier versions of providing a sound basis in the history of YAL. Like its predecessors, it is divided into two parts. The first, "That Was Then," traces the history of YAL "From Sue Barton to the Sixties" to the 1990s. The second part, "This is Now," examines the trends and themes in YAL, such as the dominance of specific genres in the YAL market.

The historical overview of YAL comprises one-third of the book's length, with Cart providing a breezy and approachable overview of YA books' origins with Maureen Daly's 1942 work Seventeenth Summer and continuing through the first golden age of the 1970s, the dire period of the 1980s and early 1990s, and the revival in the late 1990s. Cart also contextualizes YAL with information on the emergence of young adulthood, which is helpful for those unfamiliar with adolescence's brief history. While there are many titles mentioned in this first section (and throughout the book), Cart usually includes enough of a summary so that those unfamiliar with the books can understand the background and not be completely lost.

It is clear that, while Cart has great knowledge of and love for YAL's history, he wants to devote his time and the book's space to the present. Consequently, "This is Now" takes up the majority of the book and assesses the current state of affairs in YA books. The chapters here include "So, How Adult is Young Adult? The Crossover Conundrum," which looks at the liminal space between YA and adult fiction as well as the emergence of New Adult fiction, and "The New Nonfiction: The Eyes Have It," which focuses on the re-emergence and repackaging of young adult nonfiction.

Overall, this distribution of space and organization makes sense given adolescent literature's recent popularity, as well as its continuing development in complexity and range, not to mention the 
ongoing controversy surrounding it. However, these decisions sometimes lead to limitations. One of the most notable is the brevity found in the description of YAL's first golden age during the 1970s. This section offers a strong overview of Robert Cormier's work, which helped cement the period's legacy in YAL, but Cart perhaps shows an overreliance on his readers' knowledge of YA books in the list he provides to illustrate the amazing quality of work at that time. While the authors mentioned, including Lois Lowry, Judy Blume, and Walter Dean Myers, are well known and well loved, those who are not familiar with the specific titles have to take Cart's word for it when he says, "What an extraordinary roster - what an extraordinary decade!" (p. 34).

The most notable drawback in terms of organization is found in the second section, but this is most likely due to the flexibility of YAL rather than Cart's writing or approach. In many cases, such as the chapter on comics entitled "The Viz Biz: Transforming the Funnies" or the section on nonfiction, the scope of the chapters is clear. However, in other instances, the lines become more muddled. For instance, parts of "Meanwhile, Back in the Real World," which focuses on books that present true-to-life issues and topics, overlap with the following chapters on the depiction of risky behaviors, sexual activity, and LGBTQ characters and issues. While trying to write about all these topics at once would likely result in a massive chapter (and perhaps an equally massive headache for both writer and reader), the current state does make parts seem redundant.

Fortunately, the strengths of the third edition of Young Adult Literature: From Romance to Realism more than compensate for these minor organizational problems. Two of the text's greatest assets are Cart's certain voice and sound knowledge of YAL's past and present. Due to this combination, the book lends itself to multiple purposes and contexts. Cart's obvious enthusiasm for the subject makes the text accessible and interesting to those with limited background in YAL, thus making it well-suited for an undergraduate or graduate YAL class or as an introduction to YAL for teachers or librarians. Additionally, Cart's expertise in the area, reinforced by the many facts, statistics, and references used to support his contentions, offers YAL researchers and scholars an excellent resource. The 20 pages of references at the end are a veritable treasure trove for those looking for additional readings on the myriad of topics contained within YAL.

Cart's knowledge and perspective are often conveyed through his awareness of YAL's strengths and weaknesses. While he has discernible warmth for his subject, he does not have a blind allegiance to it. Rather than crafting a hagiography of YAL, he offers an honest examination of its 
history and its present state. He shows no hesitation when making potentially controversial statements, such as the limitations found in such influential works as S.E. Hinton's The Outsiders and Paul Zindel's The Pigman. On the other hand, he also proves to be a fierce advocate of YAL, particularly when it comes to defending the books from those who do not have a sound understanding of the category. His dismantling of Ruth Graham's "Against YA," which asserts that adults who read YAL should be ashamed, and Meghan Cox Gurdon's "Darkness Too Visible: Contemporary Fiction for Teens Is Rife with Explicit Abuse, Violence and Depravity” manages to strike the right balance of nuance and frankness.

Cart's opinions come out in myriad ways, and like the best critics, he presents these views with thought and care. The result is that, even when disagreeing with him, readers will likely be able to see and recognize his point of view. There are a few exceptions to this. For instance, when describing the controversy that re-emerged in the 1980s regarding who can and should write about a particular culture, he states that this "may be [a topic] that can never be satisfactorily resolved, for at its core it asks an unanswerable question: Can a writer's imagination be powerful enough to create a viable work of fiction about a culture he or she has observed only from the outside?” (p. 51). He then includes quotes from Richard Peck, Jane Yolen, and Hazel Rochman that indicate that the answer to this supposedly unanswerable question is "Yes," but he does not include any support for the opposing side. He also makes some interesting and potentially provocative assertions about political correctness, which he calls "multiculturalism without a sense of humor" (p. 52) but does not really define. Given the numerous ways that the term political correctness is used and interpreted, some additional explanation here, especially in the context of the 1980s, would be helpful. All this said, this level of candor makes this book a strong addition to a class on YAL, since it allows for discussion and debate and might encourage students to form their own opinions on these topics.

It is impossible to overstate Michael Cart's impact on young adult literature, and the third edition of Young Adult Literature: From Romance to Realism is yet another addition to his already impressive legacy. The original edition laid the groundwork for much of the YAL scholarship that is happening today, and the third edition continues its tradition while adding to the body of available work. It is an essential resource for anyone who wants to learn more about adolescent literature. 


\section{REFERENCES}

Cart, M. (1996). From Romance to Realism: 50 Years of Growth and Change in Young Adult Literature. New York: HarperCollins Publishers.

Cart, M. (2001). From insider to outsider: The evolution of young adult literature. Voices from the Middle, $9(2), 95-97$.

Cart, M. (2016). Young adult literature: From romance to realism (3rd ed.). Chicago, IL: NealSchuman Publishers.

TERRI SUICO is an assistant professor of education at Saint Mary's College in Notre Dame, Indiana. Her research focuses on depictions of gender in young adult literature. 